\title{
Hubungan Pola Makan Dan Gaya Hidup Dengan Angka Kejadian Hipertensi Pralansia Dan Lansia Di Wilayah Kerja Puskesmas I Kembaran
}

\section{Correlation Between Diet And Lifestyle To The Hypertension Occurrence Of Pre-Elderly And Elderly In Working Area Of Primary Health Center I Kembaran}

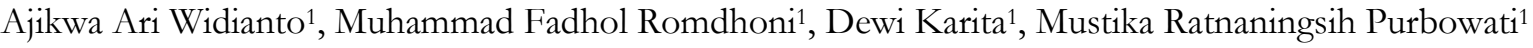 \\ ${ }^{1}$ Fakultas Kedokteran, Universitas Muhammadiyah Purwokerto
}

\begin{abstract}
Abstrak
Latar Belakang: Hipertensi sering diberi gelar The Silent Killer karena merupakan pembunuh tersembunyi yang prevalensinya sangat tinggi dan cenderung meningkat di masa yang akan datang, juga karena tingkat keganasannya yang tinggi berupa kecacatan permanen dan kematian mendadak. Di Puskesmas I Kembaran termasuk dalam data kejadian hipertensi tertinggi kedua yang dilaporkan oleh Dinkes Banyumas yaitu sebesar 2287 kasus. Banyak faktor resiko yang menyebabkan terjadinya hipertensi, terutama pola makan dan gaya hidup.

Tujuan: Mengetahui ada tidaknya hubungan pola makan dan gaya hidup dengan angka kejadian hipertensi pada pralansia dan lansia di wilayah kerja Puskesmas I Kembaran.

Metode: Obeservational analitik dengan pendekatan Cross sectional dan menggunakan teknik simple random sampling. Responden dalam penelitian ini adalah 50 responden pralansia dan lansia yang mengikuti prolanis di Puskesmas I Kembaran. Pengukuran pola makan dan gaya hidup menggunakan kuesioner dan pengukuran tekanan darah menggunakan alat sphygmomanometer. Teknik analisis data yang digunakan adalah uji chi square.

Hasil: Hasil uji Chi square mengetahui hubungan pola makan dan gaya hidup dengan angka kejadian hipertensi. Hasil analisis variabel pola makan diperoleh $p=0,003$ dan hasil analisis variabel gaya hidup diperoleh $p=0,023$.

Kesimpulan: Terdapat hubungan pola makan dan gaya hidup dengan angka kejadian hipertensi pada pralansia dan lansia di wilayah kerja Puskesmas I Kembaran, dimana pola makan dan gaya hidup yang tidak baik memicu angka kejadian hipertensi yang lebih tinggi.
\end{abstract}

Kata Kunci: Pola makan, gaya hidup, hipertensi, pralansia, lansia

\section{Abstract}

Background: Hypertension is also known as The Silent Killer since it is a hidden killer which its prevalence is very high and tends to increase in the future. Besides, its high malignancy affects in the form of permanent disability and sudden death. Primary Health Care Center (Puskesmas) I Kembaran obtained the second highest occurrence of hypertension reported by the Banyumas Health Office (Dinas Kesehatan Banyumas), consisted of 2287 cases. Many risk factors affect to hypertension, especially diet and lifestyle.

Objective: Determine whether there was a correlation between diet and lifestyle to the occurrence of hypertension in pre-elderly and elderly in the working area of Puskesmas 1 Kembaran.

Method: Analytic observational with Cross sectional approach and applied simple random sampling technique. This study was conducted by 50 pre-elderly and elderly respondents who participated PROLANIS (Chronic Disease Management Program) at Puskesmas 1 Kembaran. Questionnaire was implemented to measure the diet and lifestyle, while blood pressure was obtained by sphygmomanometer. Data analysis technique conducted was chi square test.

Result: Chi square test to determine the correlation between diet and lifestyle to the occurrence of hypertension. The results of the analysis of diet variable obtained $\mathrm{p}=0.003$ and the lifestyle variable was $\mathrm{p}=0.023$.

Conclusion: There was a correlation between diet and lifestyle to the occurrence of hypertension in pre-elderly and elderly in the working area of Puskesmas 1 Kembaran, where diet and lifestyle are not good triggers a higher occurance of hypertension.

Keywords: diet, lifestyle, hypertension, pre-elderly, elderly. 


\section{PENDAHULUAN}

Hipertensi adalah peningkatan tekanan darah sistolik lebih dari $140 \mathrm{mmHg}$ dan tekanan darah diastolik lebih dari $90 \mathrm{mmHg}$ pada dua kali pemeriksaan dengan selang waktu lima menit dalam keadaan istirahat. Menurut American Heart Association (AHA), penduduk Amerika berusia diatas 20 tahun menderita hipertensi sebanyak 74,5 juta jiwa dengan hampir 90-95\% tidak diketahui penyebabnya. Hipertensi sering diberi gelar The Silent Killer karena hipertensi merupakan pembunuh tersembunyi yang prevalensinya sangat tinggi dan cenderung meningkat di masa yang akan datang, juga karena tingkat keganasannya yang tinggi berupa kecacatan permanen dan kematian mendadak ${ }^{1}$.

Hipertensi merupakan faktor risiko primer penyebab dua kematian di Indonesia, stroke $(21 \%$ dari seluruh kematian) dan penyakit jantung iskemik (9\% dari seluruh kematian). Data statistik WHO terbaru pada tahun 2015 menyatakan bahwa sekitar 23,8\% penduduk Indonesia berusia 18 tahun ke atas mengalami hipertensi ${ }^{2}$.

Di Indonesia penyakit hipertensi terjadi penurunan yang mulanya $31,7 \%$ pada tahun 2007 menjadi 25,8\% pada tahun 2013.
Prevalensi hipertensi di Indonesia yang didapat melalui pengukuran pada umur $\geq 18$ tahun sebesar 25,8\%. Prevalensi tertinggi di Bangka Belitung (30,9\%),

diikuti Kalimantan Selatan (30,8\%), Kalimantan Timur (29,6\%) dan Jawa Barat (29,4\%). Secara keseluruhan, prevalensi hipertensi di Indonesia sebesar 26,5\%33. Persentase hipertensi pada pengukuran usia $\geq 18$ tahun menurut kabupaten/kota di Jawa Tengah sebesar $11,55 \%$

Ada beberapa faktor risiko yang dapat menyebabkan hipertensi antara lain karakteristik individu (usia, jenis kelamin, riwayat penyakit hipertensi), pola makan (kebiasaan konsumsi lemak, natrium, dan kalium), dan gaya hidup (kebiasaan merokok, konsumsi alkohol, stress, konsumsi kopi dan aktivitas fisik) ${ }^{5}$.

Keadaan hipertensi ketika tidak terkontrol dapat menyababkan komplikasi kerusakan organ lain. Untuk mencegah terjadinya komplikasi yang menyebabkan kerusakan organ lain pada lansia yang menderita hipertensi, pencegahan dapat dilakukan melalui beberapa aspek, antara lain pengaturan pola makan seperti diet rendah garam, pengaturan obesitas dan modifikasi gaya 
hidup. Perubahan gaya hidup sangat erat kaitannya dengan pengetahuan masing-masing individu untuk mencegah terjadinya hipertensi ${ }^{6}$.

Data dari Dinas Kesehatan Provinsi Jawa Tengah, rekapitulasi kasus baru PTM di Jawa Tengah tahun 2016 secara keseluruhan dilaporkan sebanyak 943.927 kasus. Proporsi terbanyak dari penyakit tidak menular masih diduduki oleh hipertensi yaitu sebesar 60\%. Kejadian hipertensi sebanyak 24.446 kasus pada perhitungan kasus penyakit tidak menular di Pusksemas dan Rumah Sakit Kabupaten/Kota Banyumas 2017. Puskesmas I Kembaran termasuk dalam data kejadian hipertensi tertinggi kedua yang dilaporkan oleh Dinkes Banyumas yaitu sebesar 2287 kasus?.

METODE

Penelitian ini menggunakan desain crosssectional dengan data primer yaitu pengisian kuesioner pola makan dan gaya hidup serta pengukuran tekanan darah. Responden dalam penelitian ini adalah 50 responden pralansia dan lansia yang mengikuti prolanis di Puskesmas I Kembaran. Pola makan dan gaya hidup diukur dengan menggunakan kuesioner dan dikategorikan baik dan tidak baik, sedangkan tekanan darah diukur menggunakan alat tensi meter atau sphygmomanometer dan kemudian dikategorikan hipertensi dan tidak hipertensi. Kuesioner pola makan dan gaya hidup merujuk dari penelitian Romauli pada tahun 2014.

Uji normalitas data yang digunakan yaitu Saphiro Wilk. Jika data terdistribusi normal, maka data akan dianalisis dengan uji Chi Squre, apabila data yang diperoleh tidak terdistribusi dengan normal maka akan dilakukan analisis dengan uji fisher. Nilai $\mathrm{p}<0.05$ digunakan untuk menentukan level signifikansi.

Hubungan antara pola makan dan gaya hidup di analisis menggunakan uji pearson chi square. Nilai $\mathrm{p}<0.05$ digunakan untuk menentukan level signifikansi

\section{HASIL}

Responden yang ikut serta dalam penelitian ini adalah responden yang mengikuti kegiatan Prolanis di wilayah kerja Puskesmas I Kembaran. Data distribusi responden penelitian berdasarkan karakteristik di wilayah kerja Puskesmas I Kembaran dapat dilihat pada tabel 1 dan tabel 2.

Hasil dari pengumpulan data distribusi responden, didapatkan data pralansia sebanyak 
21 orang dan lansia sebanyak 29 orang. Pada responden pralansia, sebagian besar responden memiliki jenis kelamin perempuan sebesar 90,5\% dan pada lansia sebagian besar adalah perempuan sebesar 82,8\%. Pada kategori pendidikan, responden pralansia secara keseluruhan berpendidikan akhir dasar/menengah sebesar $100 \%$ dan pada lansia sebagian besar berpendidikan akhir dasar/menengah sebesar 96,6\%. Pada kategori pekerjaan, pada pralansia sebagian besar responden memiliki pekerjaan lain-lain (perempuan sebagai ibu rumah tangga dan lakilaki tidak bekerja) sebesar $61,9 \%$ dan pada lansia sebagian besar responden memiliki pekerjaan lain-lain (perempuan sebagai ibu rumah tangga dan laki-laki tidak bekerja) sebesar 72,4\%.

Data distribusi responden berdasarkan variabel yang diteliti yaitu pola makan, gaya hidup dan keadaan hipertensi dapat dilihat pada tabel 3 .

Hasil dari pengumpulan data distribusi responden berdasarkan variabel yang diteliti, kategori hipertensi pada penelitian ini dibagi menjadi dua, yaitu hipertensi dan tidak hipertensi. Hasil dari tabel di atas didapatkan distribusi kelompok responden pralansia lebih banyak terjadi hipertensi sebesar $61,9 \%$ dan kelompok lansia lebih banyak mengalami hipertensi sebesar 51,7\%. Pada variabel pola makan, kelompok pralansia lebih banyak responden dengan pola makan baik sebesar $76,2 \%$ dan pada kelompok lansia lebih banyak responden dengan pola makan baik sebesar 58,6\%. Variabel gaya hidup kelompok pralansia lebih banyak responden dengan gaya hidup baik sebesar 57,1\% dan pada kelompok lansia lebih banyak responden dengan gaya hidup tidak baik sebesar $55,2 \%$.

Hasil analisis pola makan dengan kejadian hipertensi menunjukkan nilai $\mathrm{p}=0,003 \quad(p<0,05)$ hal ini berarti bahwa terdapat hubungan pola makan dengan kejadian hipertensi. Pada analisis gaya hidup menunjukkan nilai $\mathrm{p}=0,023(p<0,05)$ hal ini berarti bahwa terdapat hubungan gaya hidup dengan kejadian hipertensi.

\section{DISKUSI}

Hasil analisis uji chi square menunjukkan nilai $\mathrm{p}<0,05$ pada kedua variabel yang berarti bahwa terdapat hubungan antara pola makan dan gaya hidup dengan kejadian hipertensi pada pralansia dan lansia di wilayah kerja Puskesmas I Kembaran. 
Hal ini sesuai dengan penelitian Bidjuni dan Malara tahun 2013 di Puskesmas Kolongan Kecamatan Kalawat Kabupaten Minahasa Utara yang menyatakan bahwa ada hubungan yang bermakna antara gaya hidup dalam bentuk konsumsi makanan dengan kejadian hipertensi di Puskesmas Kolongan Kecamatan Kalawat Kabupaten Minahasa Utara ${ }^{8}$.

Pola makan yang tidak baik dapat menyebabkan terjadinya hipertensi. Pola makan yang tidak baik seperti makanan yang mengandung tinggi lemak jenuh, tinggi garam, kurang sayur dan buah serta makanan dan minuman kaleng memicu terjadinya penyakit hipertensi dikarenakan makanan tersebut tidak sesuai dengan kalori yang dibutuhkan dan mengandung banyak bahan pengawet?

Pola makanan yang tidak seimbang antara asupan dengan kebutuhan bisa menyebabkan obesitas. Obesitas meningkatkan risiko terjadinya hipertensi. Masyarakat di sini lebih banyak mengkonsumsi daging dibanding dengan yang mengkonsumsi jeroan atau makanan bersantan. Kebiasaan makan daging dan konsumsi lemak tak jenuh erat hubungannya dengan peningkatan berat badan yang berisiko tinggi terjadinya hipertensi.
Minuman yang mengandung kafein juga berperan dalam terjadinya hipertensi. Kafein yang terdapat pada kopi dapat meningkatkan kadar plasma beberapa stres hormon yang diketahui dapat meningkatkan keadaan tekanan darah. Masyarakat di sini tidak mempunyaki kebiasaan konsumsi kopi secara rutin, hanya saja mengkonsumsi teh yang juga mengandung kafein $^{10}$.

Pada penelitan ini, gaya hidup juga berhubungan dalam kejadian hipertensi dengan nilai $p=0,023 \quad(p<0,05)$. Hasil tersebut sesuai dengan penelitian yang telah dilakukan oleh Dwi tahun 2016 yang dilakukan di Puskesmas Demak II dengan $\mathrm{p}=0,013$ yang menyatakan bahwa terdapat hubungan yang signifikan antara gaya hidup aktifitas fisik dengan tingkat hipertensi ${ }^{11}$. Pada penelitian ini diperoleh bahwa kelompok yang memiliki gaya hidup tidak baik lebih banyak mengalami hipertensi yaitu sebesar 64,3\%, sedangkan pada kelompok responden yang tidak hipertensi memiliki gaya hidup baik lebih banyak yaitu sebesar 68,2\%. Hal ini menunjukkan bahwa responden yang memiliki hipertensi banyak yang tidak melakukan olahraga setiap hari ataupun berolahraga $\geq 30$ menit dalam sehari dan tidak melakukan aktifitas 
pekerjaan rumah seperti mencuci, membersihkan rumah $\geq 30$ menit dalam sehari. Selain itu juga memiliki gangguan tidur sehingga mudah terbangun, susah tidur dan tidur tidak teratur $>2$ kali dalam seminggu. Gaya hidup lainnya yang lebih dominan pada penderita hipertensi adalah kebiasaan merokok. Hal ini membuktikan responden yang masih kurang dalam aktifitas fisik, kebiasaan istirahat dan memiliki kebiasaan merokok memicu terjadinya hipertensi.

Aktivitas fisik yang cukup dan teratur dapat mengurangi risiko terhadap penyakitpenyakit jantung dan pembuluh darah. Aktivitas fisik yang dianjurkan bagi penderita hipertensi adalah aktivitas sedang (yang membutuhkan oksigen 40\%) selama 30-60 menit setiap hari dalam 2 sampai 3 minggu. Kalori yang terbakar sedikitnya 150 kalori perhari. Salah satu yang bisa dilakukan adalah aerobik. Suatu aktivitas, baik itu kegiatan sehari-hari ataupun olahraga, dikatakan aerobik jika dapat meningkatkan kemampuan kerja jantung, paru-paru, dan otot$\operatorname{otot}^{12}$

Penelitian lain yang dilakukan oleh Kumar tahun 2015 di bagian barat Uttar Pradesh India menyatakan bahwa 39,8\% seseorang mengalami hipertensi pada seseorang yang tidur 6-8 jam perhari dan 34,6\% mengalami hipertensi pada seseorang yang tidur $<6$ jam perhari. Dibandingkan pada penelitian ini, seseorang akan mengalami hipertensi baik pada hipertensi tingkat 1 maupun hipertensi tingkat $2^{13}$.

Penelitian dalam jurnal Hypertension menyatakan bahwa seseorang yang hanya tidur 6 jam sehari, $42 \%$ cenderung mengalami hipertensi, sedangkan yang terbiasa tidur tidak lebih dari 6 jam risikonya 31\% mengalami hipertensi. Durasi tidur yang singkat $(<7$ jam $)$ perhari memiliki hubungan beresiko terhadap hipertensi ${ }^{14}$.

Gangguan pola tidur menandakan individu mengalami perubahan jumlah dan kualitas tidurnya sehingga mengganggu gaya hidup yang mereka inginkan. Gejalanya berupa perasaan lelah, mudah gelisah, lesu, apatis, kehitaman disekitar mata, kelopak mata membengkak, konjungtiva merah, sakit kepala dan mengantuk.

Selain itu, gaya hidup lainnya adalah kebiasaan merokok. Hubungan antara rokok dengan peningkatan risiko kardiovaskuler telah banyak dibuktikan. Selain dari lamanya, risiko merokok terbesar tergantung pada jumlah rokok 
yang dihisap perhari. Seseorang lebih dari satu pak rokok sehari menjadi 2 kali lebih rentan hipertensi dari pada mereka yang tidak merokok $^{15}$.

Merokok dapat mengganggu kerja paruparu yang normal, karena hemoglobin lebih mudah membawa karbondioksida daripada membawa oksigen. Banyak zat yang berbahaya yang terkandung dalam rokok seperti nikotin dan karbonmonoksida Kandungan nikotin dalam rokok yang terbawa dalam aliran darah dapat memengaruhi berbagai bagian tubuh yaitu mempercepat denyut jantung sampai 20 kali lebih cepat dalam satu menit daripada dalam keadaan normal. Hal ini karena nikotin menyebabkan vasokonstriksi pembuluh darah perifer ${ }^{16}$. berperan dalam peningkatan tekanan darah. Hal ini dikarenakan oksigen lebih banyak terikat oleh karbonmonoksida sehingga jantung berusaha untuk memompa oksigen yang dibutuhkan oleh organ tubuh yang membutuhkan ${ }^{17}$.

Pada penelitian ini, populasi dari pralansia dan lansia di wilayah kerja Puskesmas I Kembaran memiliki pola makan dan gaya hidup yang tidak baik baik dari segi jumlah dan jenis asupan makanan, gaya hidup sepertei beraktifitas fisik yang cukup, istirahat yang cukup maupun dari kebiasaan merokok, sehingga memicu terjadinya hipertensi.

\section{KESIMPULAN}

Terdapat hubungan antara pola makan dan gaya hidup dengan angka kejadian hipertensi pada pralansia dan lansia di wilayah

kerja Puskesmas I Kembaran.

KONFLIK KEPENTINGAN (Conflict of Interest)

Berdasarkan panduan dari International Committee of Medical Joumal Editors (ICMJE), penelitian ini tidak memiliki unsur konflik kepentingan.

\section{UCAPAN TERIMAKASIH}

Dokter Fadhol, dokter Dewi, dokter Mustika dan seluruh dosen dan sivitas akademika Fakultas Kedokteran Universitas Muhammadiyah Purwokerto yang tidak bisa disebutkan satupersatu, terima kasih dukungan dan nasihatnya selama proses pembuatan skripsi dan naskah publikasi. 
Seluruh perangkat Puskesmas 1

Kembaran beserta perangkatnya yang telah memberikan informasi guna mempermudah jalannya proses penelitian.

\section{DAFTAR PUSTAKA}

1. Kemenkes RI (2014) Mencegah dan Mengontrol Hipertensi agar Terhindar dari Kerusakan Organ jantung. Otak dan Ginjal. Pusat Data dan Informasi Kementerian Kesehatan RI, pp. 3-4. doi: 10.1177/109019817400200403.

2. WHO (2015) Prevalence of Raised Blood Pressure.

3. Riset Kesehatan dasar (2015) Badan Penelitian dan Pengembangan Kesehatan Kementrian RI.

4. Dinas Kesehatan Provinsi Jawa Tengah (2015) Profil Kesehatan Provinsi Jawa Tengah

5. Ernitasari, P. D., Djarwoto, B. and Siswati, T. (2009) Pola makan, rasio lingkar pinggang pinggul (RLPP) dan tekanan darah di Puskesmas Mergangsan Yogyakarta. Jurnal Gizi Klinik Indonesia. doi: 10.22146/IJCN.17714.

6. Sudoyo, A. W. et al. (2014) Buku Ajar Ilmu Penyakit Dalam Jilid 3, Interna Publishing.

7. Dinas Kesehatan Kabupaten Banyumas (2017) Kasus Penyakit Tidak Menular Di Puskemas Dan Rumah Sakit Kabupaten/Kota Banyumas 2017. Purwokerto.

8. Suoth, M., Bidjuni, H. and Malara, R. T. (2014) Hubungan Gaya Hidup dengan Kejadian
Hipertensi di Puskesmas Kolongan Kecamatan Kalawat Kabupaten Minahasa Utara. ejournal keperawatan (e-Kp), 2(1), pp. 110.

9. Muhammadun, A. . (2010) Hidup Bersama Hipertensi. Jakarta: In-Books

10. Winkelmayer, W. C. et al. (2005) Habitual caffeine intake and the risk of hypertension in women. $J A M A$ : the journal of the American Medical Association. doi: 10.1001/jama.294.18.2330.

11. Dwi, L. (2016) Faktor-faktor yang Berbubungan dengan Tingkat Hipertensi di Wilayah Kerja Puskesmas Demak II

12. Braunwald Libby, P, Bonow, R, Mann, D, Zipes, D, E. (2008) Braunwald's heart disease: a textbook of cardiovascular medicine, Heart disease.

13. Kumar (2015) Correlation Of Dietary Habits, Physical Activity And Hypertension In Administrative Officers In Western Uttar Pradesh. Journal of Evolution of Medical and Dental Sciences, 4(66), pp. 11493-11499. doi: 10.14260/jemds/2015/1659.

14. Buxton OM, M. E. (2010) Short and long sleep are positively associated with obesity, diabetes, hypertension, and cardiovascular disease among adults in the United States. Soc Sci Med, 71(5), pp. 1027-36.

15. Price, Sylvia Anderson, dan Wilson, L. M. (2006) Hipertensi in Patofisiologi: Konsep Klinis Proses-Proses Penyakit. Jakarta: Penerbit Buku EGC.

16. Bustan, M. . (2007) Epidemiologi Penyakit Tidak Menular. Jakarta: Rineka Cipta

17. Lam, M. B. S. (2011) Perawatan Penderita Hipertensi di Rumah oleh Keluarga Suku Batak dan Suku Jawa di Keluraban Lau Cimba Kabanjabe 
Lampiran. TABEL

Tabel 1. Distribusi responden bersdasarkan karakteristik usia Usia Persen (\%)

\begin{tabular}{lr}
\hline a. Pralansia & 42 \\
b. Lansia & 58 \\
\hline Total & $\mathbf{1 0 0}$ \\
\hline
\end{tabular}

Tabel 2. Distribusi responden bersdasarkan karakteristik responden

$\begin{array}{ccc}\text { Karakteristik } & \text { Pra Lansia } & \text { Lansia } \\ & \text { Persen (\%) } & \text { Persen (\%) }\end{array}$

\begin{tabular}{lcc}
\hline 1.Jenis Kelamin & & \\
a. Laki-laki & 9,5 & 17,2 \\
b. Perempuan & 90,5 & 82,8 \\
\hline$\quad$ Total & $\mathbf{1 0 0}$ & $\mathbf{1 0 0}$ \\
\hline 2. Pendidikan & 100 & \\
a. Dasar/ menengah & 0 & 96,6 \\
b. Perguruan Tinggi & $\mathbf{1 0 0}$ & 3,4 \\
\hline$\quad$ Total & & $\mathbf{1 0 0}$ \\
\hline 3. Pekerjaan & 9,5 & \\
a. Pegawai Swasta & 14,3 & 0 \\
b. Petani & 0 & 6,9 \\
c. Pedagang & 14,3 & 6,9 \\
d. Buruh & 61,9 & 13,8 \\
e. Lain-lain & $\mathbf{1 0 0}$ & $\mathbf{7 2 , 4}$ \\
\hline Total & & $\mathbf{1 0 0}$ \\
\hline
\end{tabular}

Tabel 3. Distribusi responden berdasarkan variabel yang diteliti

\begin{tabular}{lcc}
\hline \multicolumn{1}{c}{ Variabel } & $\begin{array}{c}\text { PraLansia } \\
\text { Persen (\%) }\end{array}$ & $\begin{array}{c}\text { Lansia } \\
\text { Persen (\%) }\end{array}$ \\
\hline 1. Kejadian Hipertensi & 61,9 & \\
a. Hipertensi & 38,1 & 51,7 \\
b. Tidak Hipertensi & $\mathbf{1 0 0}$ & 48,3 \\
\hline$\quad$ Total & 23,8 & $\mathbf{1 0 0}$ \\
\hline 2. Pola Makan & 76,2 & 41,4 \\
a. Tidak Baik & $\mathbf{1 0 0}$ & 58,6 \\
b. Baik $\quad$ & $\mathbf{1 0 0}$ \\
\hline$\quad$ Total & 42,9 & \\
\hline 4. Gaya Hidup & 57,1 & 55,2 \\
a. Tidak Baik & $\mathbf{1 0 0}$ & 44,8 \\
b. Baik $\quad$ Total & & $\mathbf{1 0 0}$ \\
\hline
\end{tabular}


Tabel 4. Hasil Uji analisis chi square pola makan dan gaya hidup dengan angka kejadian hipertensi

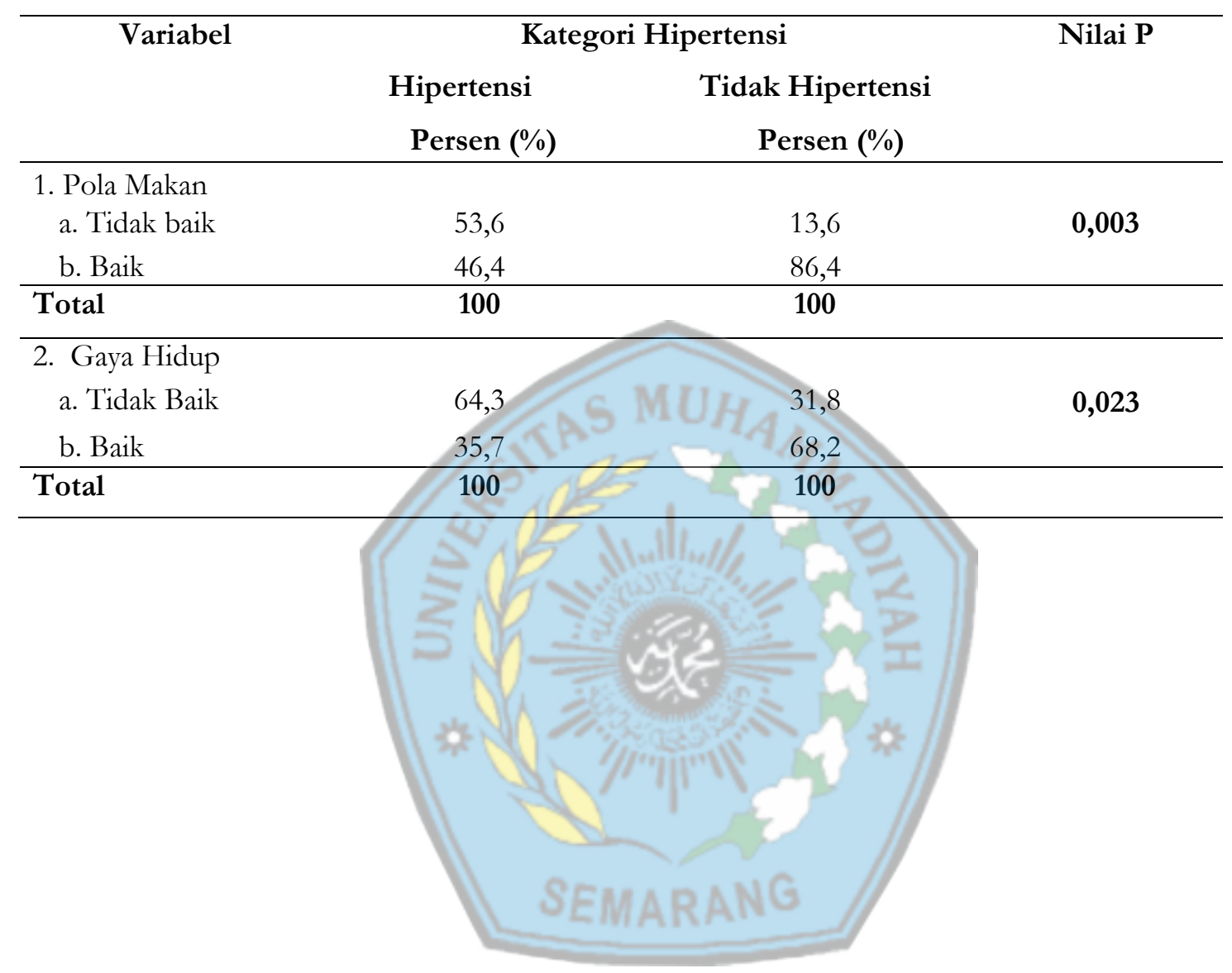

